\title{
Technical Standards and Guidelines for Huntington Disease Testing
}

Nicholas T. Potter, PhD ${ }^{2}$, Elaine B. Spector, PhD ${ }^{2,3}$, Thomas W. Prior, PhD ${ }^{1-3}$

\begin{abstract}
One mission of the ACMG Laboratory Quality Assurance (QA) Committee is to develop standards and guidelines for clinical genetics laboratories, including cytogenetics, biochemical, and molecular genetics specialties. This document was developed under the auspices of the Molecular Subcommittee of the Laboratory QA Committee by the Huntington Disease (HD) Working Group. These guidelines are not to be interpreted as restrictive or the only approach but to provide a helpful guide. Certainly, appropriately trained and credentialed laboratory directors have flexibility to utilize various testing platforms and design testing strategies with considerable latitude. We felt that it was essential to include technique-specific guidelines of several current technologies commonly used in laboratories providing HD testing, because the technologies discussed are available commercially and are widely utilized. We take the view that these technologies may change, and thus this document may change with future review. Genet Med 2004:6(1):61-65.
\end{abstract}

Key Words: Huntington disease, genetic testing, medical genetics, HD, molecular diagnostics

\section{HD1 INTRODUCTION}

Disease-specific statements are intended to augment the current general ACMG Standards and Guidelines for Clinical Genetics Laboratories. Individual laboratories are responsible for meeting the CLIA/CAP quality assurance standards with respect to appropriate sample documentation, assay validation, general proficiency, and quality control measures.

\section{HD2 BACKGROUND ON HUNTINGTON DISEASE}

HD2.1 Gene symbol/chromosome locus: HD; also IT-15 gene. HD2.2 OMIM number: 143100.

HD2.3 Brief clinical description: HD is a neurodegenerative disease of midlife onset that produces choreic movements and cognitive decline, often accompanied by psychiatric changes. It affects approximately 1 in 10,000 individuals. Juvenile-onset HD occurs in about $5 \%$ of affected patients, is a rapidly progressive variant and presents with rigidity, spasticity, and intellectual decline before the age of 20 . The symptoms result from the selective loss of neurons, most notably in the caudate nucleus and putamen, and there is currently no effective treatment. For more information see the online Gene Reviews profile at www.genereviews.org.

From ${ }^{1}$ Molecular Subcommittee of the Laboratory Quality Assurance Committee, ${ }^{2} \mathrm{Hunting}$ ton Disease Molecular Working Group, and ${ }^{3}$ Laboratory Quality Assurance Committee, Bethesda, Maryland.

Approved by the Board of Directors of the American College of Medical Genetics, June 27, 2003.

American College of Medical Genetics, 9650 Rockville Pike, Bethesda, MD 20814-3998.

Go to www.geneticsinmedicine.org for a printable copy of this document.

See disclaimer at the end of this article.

DOI: 10.1097/01.GIM.0000106165.74751.15
HD2.4 Mode of inheritance: Inheritance is autosomal dominant with clinical manifestations associated with expansion of a polymorphic trinucleotide (CAG) repeat. Variable penetrance for alleles carrying 36 to 39 repeats has been noted, but the disease appears fully penetrant when the repeat numbers are $\geq 40$.

HD2.5 Gene description/normal gene product: The IT-15 gene spans over $200 \mathrm{~kb}$ and contains 67 exons. The encoded protein, huntingtin, consists of 3136 amino acids residues, has a molecular weight of $350 \mathrm{kD}$, and lacks homology to any previous known proteins. The entire genomic region has been sequenced, and the CAG expansion mutation is located in exon 1. Structural analysis of the HD gene promoter region is consistent with the gene being a housekeeping gene. Although on a cellular level mutant huntingtin is widely expressed in both neural and nonneural tissue, there is regional-specific neuronal loss in the neurons in the caudate and putamen.

HD2.6 Genotype/phenotype association: The inverse relationship between the CAG repeat size (at greater or equal to 40 repeats) and age of onset is unequivocal. The relationship is particularly strong for high repeat sizes ( $>50$ repeats). However, the repeat length does not allow precise prediction of the age of onset for any one particular patient.

HD2.7 Mutational mechanism: HD is caused by a toxic gain of function mechanism. The gain of function could be due to either an over-activity of the normal function, or perhaps the introduction of a novel function of the protein. The pathogenic process in relation to the expansion may involve a novel interaction with other proteins or multimerization of the protein leading to large insoluble aggregates. Intranuclear inclusions of the truncated mutant protein aggregates have been identified in brains of HD patients. These alterations are ulti- 
mately associated with, but not necessarily causative of, cell death.

HD2.8 Listing of mutations: Allelic heterogeneity has not been described in HD.

HD2.9 Ethnic association of HD mutation: All major ethnic groups appear to be susceptible to expansion of the HD CAG repeat.

\section{HD3 SPECIAL TESTING CONSIDERATIONS}

HD3.1 Sensitivity and specificity: CAG-repeat expansion mutations account for $>99 \%$ of cases of HD. Therefore, tests that effectively detect and measure the CAG-repeat region of the IT-15 gene are $>99 \%$ sensitive. The absence of HD pathology has not been documented in any individual with an HD allele size of $\geq 40$ CAG repeats who died, disease-free, after living up to or past the normal life expectancy. Therefore, positive results (at least one allele of $40 \mathrm{CAG}$ repeats or greater) are $100 \%$ specific. Allele sizes of 26 CAG repeats and lower have never been associated with a HD phenotype in the U.S. survey or in any published study. Allele sizes of 27 to 35 CAG repeats are rare and have not been associated convincingly with an $\mathrm{HD}$ phenotype, but may be mutable as described in section 4.1.2. Allele sizes of 36 to 39 CAG repeats have been reported in both clinically affected and clinically unaffected individuals. Thus, it is not possible to determine the specificity of the test when one or both of the alleles are in the 36 to 39 CAG repeat range.

HD3.2 Diagnostic versus predictive testing: This test is used for both confirmatory and predictive testing. Positive results for both confirmatory and predictive testing are considered diagnostic. It is strongly suggested that predictive testing not be offered to individuals until they are at least 18 years of age. A formal multidisciplinary predictive testing protocol is offered at many sites for individuals desiring a determination of their carrier status.

HD3.3 Prenatal testing: This test can be used for prenatal diagnosis in both amniotic fluid cells and chorionic villus samples (CVS). DNA samples should be obtained from both parents and run simultaneously with the prenatal sample. Maternal cell contamination studies should be performed on every prenatal sample to confirm the fetal origin of the sample being tested. In some extraordinary cases, simultaneous predictive and/or confirmatory testing on a parent of the fetus and the fetus itself can be performed.

\section{HD4 GUIDELINES}

\section{HD4.1 Definition of normal and mutation category}

(Fig. 1)

HD4.1.1 Normal alleles: Normal alleles are defined as alleles with $\leq 26$ CAG repeats. ${ }^{1}$ These alleles are not pathological and segregate as a stable polymorphic repeat in $>99 \%$ of meiosis. The most common normal allele lengths contain 17 and 19 CAG repeats. ${ }^{2}$

HD4.1.2 Mutable alleles: Mutable normal alleles are defined as alleles with 27 to 35 CAG repeats, and this repeat range is

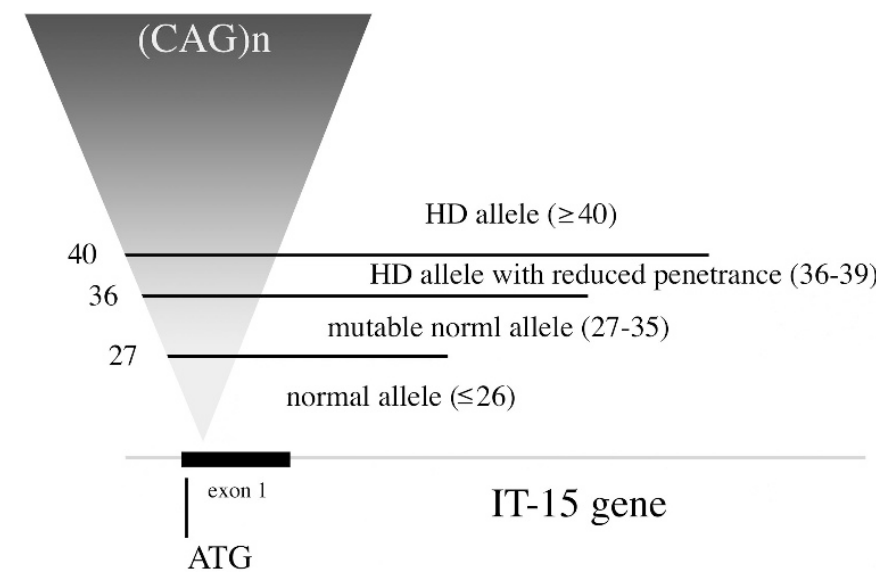

Fig. 1 Diagram of IT-15 gene and the location of the polymorphic CAG repeat within exon 1. Boundaries denote CAG repeat length categories and descriptors.

often referred to as the meiotic instability range or as "intermediate alleles." These alleles have yet to be convincingly associated with a HD phenotype, but they can be meiotically unstable in sperm, and pathological expansion of paternally derived alleles in this size range has been described. ${ }^{3,4}$ There have been no reports of maternally transmitted alleles in this range producing offspring with affected alleles. ${ }^{5}$ Approximately $1.5 \%$ to $2 \%$ of the general population carry alleles in this size range. ${ }^{2,6}$ The likelihood that transmission of an allele in this range will expand into an HD allele is dependent upon several factors, including sex of the transmitting individual, the size of the allele, the molecular configuration of the region surrounding the CAG repeat, and its haplotype. ${ }^{6,7}$ This risk may be as high as $6 \%$ to $10 \%$ for paternal alleles carrying a CAG repeat of $35 .^{7}$

HD4.1.3 HD alleles with reduced penetrance: $\mathrm{HD}$ alleles with reduced penetrance are defined as alleles with 36 to 39 CAG repeats. Repeat sizes in this range are often referred to as being in the reduced penetrance range. Alleles in this size range are meiotically unstable and are associated with the HD phenotype in both clinically and neuropathologically documented cases. ${ }^{1}$ However, in rare cases, alleles in this range have been found in elderly asymptomatic individuals. ${ }^{8,9}$ Although the limited number of documented cases has precluded the development of empirical penetrance risks for alleles in this range, some estimates of risk can be ascertained from an examination of individual case reports. ${ }^{8,9}$

HD4.1.4 HD alleles with full penetrance: HD alleles with full penetrance are defined as alleles with $\geq 40$ CAG repeats. Although there are several reports of elderly, clinically asymptomatic HD gene carriers with 36 to 39 CAG repeats, ${ }^{9}$ there are no reports of the absence of HD pathology in any individual with $\geq 40$ CAG repeats. The largest expanded HD allele detected to date carries $\approx 250$ CAG repeats in a patient with juvenile-onset disease. ${ }^{10}$

HD4.1.5 Mosaicism: Mosaicism due to both mitotic as well as meiotic instability has been described in brain and sperm and appears to be more pronounced in juvenile-onset cases of 
HD associated with larger CAG expansions. ${ }^{11}$ However, the degree of mosaicism is not significant enough to compromise the interpretation of CAG repeat lengths determined from DNA extracted from peripheral blood lymphocytes.

\section{HD4.2 Methodological considerations}

Individual U.S. laboratories offering molecular diagnostic testing for HD should be in compliance with all federal and state regulations relevant to clinical laboratory operations. This includes meeting all CLIA/CAP quality control requirements. In addition, all laboratories should be active participants in annual HD proficiency testing challenges. All methodological applications should also be in compliance with the Standards and Guideline for Clinical Genetics Laboratories developed by the Laboratory Quality Assurance Committee of the American College of Medical Genetics. ${ }^{12}$ Non-US laboratories should be similarly compliant with their individual countries' statutory regulations governing oversight of clinical laboratories.

\section{HD4.2.1 PCR methods}

HD4.2.1.1 Several sets of primers, PCR conditions, amplicon separation, and detection techniques have been published. ${ }^{13-17}$ Regardless of the particular PCR-based strategy selected, it is important that assay conditions and post-PCR analyses be optimized to ensure the accurate and unambiguous quantitation of repeat length (Fig. 2, A and B). It should be noted that CAG sizing anomalies have been observed in both comparative studies of ${ }^{32} \mathrm{P}$ incorporation methods ${ }^{8}$ and in comparative post-PCR analyses utilizing agarose, capillary, and denaturing polyacrylamide gel electrophoretic methods. ${ }^{18-20}$ As such, accurate quantitation of patient amplicon sizes should be empirically determined by comparison to appropriate external or internal standards. These could include, but are not limited to, (M13) sequencing ladders, cloned reference standards, and appropriate normal and abnormal patient controls whose sizes have been independently verified. As it is the length of the polymorphic CAG repeat alone that is associated with the HD phenotype, patient genotyping based upon the use of a single primer pair that amplifies both the CAG and the adjacent CCG repeat ${ }^{17}$ is discouraged. The CCG repeat, which lies $3^{\prime}$ of the HD CAG repeat, has been shown to be polymorphic and as a result may lead to diagnostic inaccuracies for both normal and HD allele sizing.

HD4.2.1.2 Appropriate controls that include a range of CAG sizes should be utilized for each analysis. It is the responsibility of the laboratory to empirically determine the detection limits for their assays. Although the upper limit of detection is not known, alleles carrying $\approx 115 \mathrm{CAG}$ repeats have been amplified by PCR-based methods ${ }^{21}$ (S.V. Sørensen, University of Copenhagen, personal communication, 2003), whereas alleles carrying greater than $\approx 125 \mathrm{CAG}$ repeats appear to be refractory to reproducible amplification ${ }^{10}$ (D. Barden, University of Washington, personal communication, 2003).

HD4.2.1.3 Polymorphisms surrounding or within the CAG tract have been identified and have a collective frequency of $>$ $1 \%$ in patients referred for $\mathrm{HD}$ testing. ${ }^{6,7,22-26}$ These nucleotide substitutions can generally be categorized into two groups: those that modify primer-annealing sites and those that result
$\mathbf{A}$

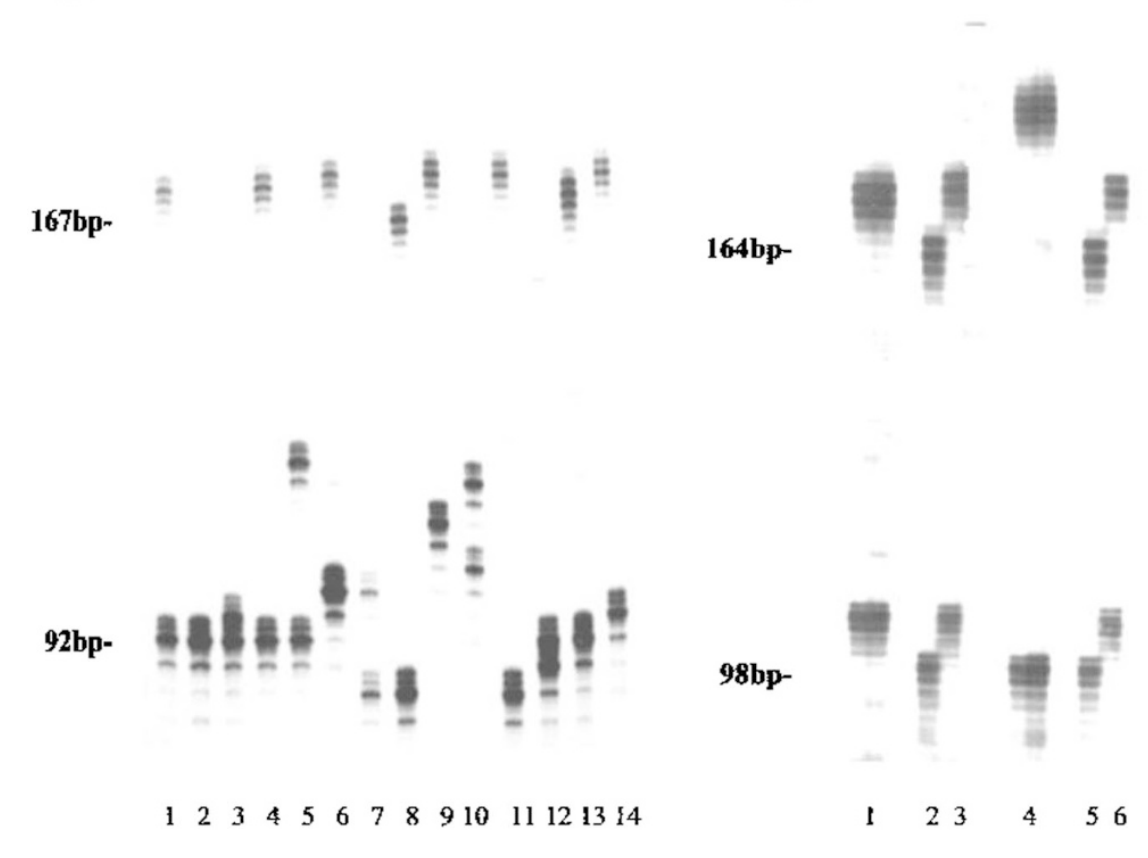

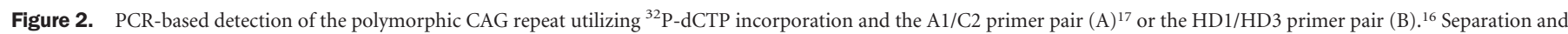

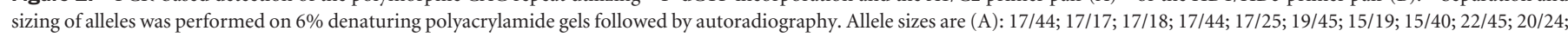

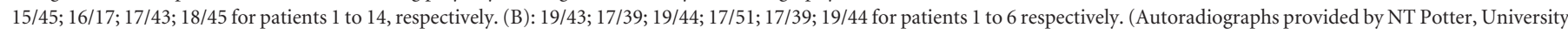
of Tennessee Medical Center) 
in the loss of interruption between the CAG and CCG tracts. In the first category, nucleotide changes can result in the misinterpretation of genotyping data due to an allele-specific amplification failure associated with primer misannealing. As such, in certain clinical circumstances "apparent homozygosity" for two normal alleles should be interpreted with caution, and the use of alternative primer pairs or other methodologies (Southern blot or sequencing) should be used to resolve any ambiguous results. ${ }^{22-26}$ In the second category, a rare A to G substitutions in the intervening 12-bp segment between the CAG and CCG tracts (CAGCAGCCGCCG) can result in increased meiotic instability of the tract as well as a miscalculation of uninterrupted CAG repeat length based upon conventional calculation formulas. 7,25

HD4.2.2 Southern blot: Southern blot protocols are occasionally useful for the identification of large expansions (which may fail to amplify well) associated with juvenile-onset HD, and are useful for the confirmation of "homozygous normal" genotypes. ${ }^{27}$ It is recommended that all laboratories consider the use of such protocols or establish a formal referral arrangement with a facility that offers this testing for those cases that require genotypic resolution.

\section{HD4.3 Interpretations}

Since 1998, it has been the intent of the CAP/ACMG Biochemical and Molecular Genetics Resource Committee to standardize the accuracy of CAG repeat quantitation. For the reporting of $\mathrm{HD}$ results, it is the recommendation of the Committee that each laboratory be able size HD alleles with the following accuracy: \pm 1 repeat for alleles $\leq 43 ; \pm 2$ repeats for alleles between 44 and 50 ; \pm 3 repeats for alleles between 51 and 75 ; and \pm 4 repeats for alleles $>75$.

HD4.3.1 Elements considered essential to the reporting of clinical test results are described in detail in the ACMG Standards and Guidelines for Clinical Genetics Laboratories. The following additional elements should also be included in the reporting of an HD genotype.

HD4.3.1.1 The methodology used to assign the genotype. If PCR methodology was used, then a description of the primer pair(s) should be included as well as the method of amplicon separation and detection. Furthermore, each report should contain a statement regarding PCR sensitivity for the detection of large expansions. If a Southern blot was required, the restriction enzyme(s) and probe(s) should be identified. Each report must state the CAG repeat length categories and descriptors currently utilized in clinical practice, and each reportable genotype should be classified and interpreted using these categorical definitions.

HD4.3.1.2 Each report must include the CAG repeat numbers of both alleles with the precision of sizing fulfilling the criteria recommended by the CAP/ACMG Biochemical and Molecular Genetics Resource Committee. For large alleles determined by PCR and/or Southern blot, qualifying terms such as "approximately" or "estimated" can be used but should not be written as to create any unnecessary interpretive ambiguity.
All positive results should state that genetic counseling is indicated and testing is available for other at-risk family members.

HD4.3.2 The following points on alternative diagnoses may be included.

HD4.3.2.1 HD phenocopies represent $\approx 3 \%$ of patients referred for molecular confirmation of a clinical diagnosis of HD, ${ }^{28,29}$ and several other loci (HDL1 and HDL2) have recently been identified. ${ }^{30-32}$ As such, IT-15 gene expansion in these patients will be negative. Furthermore, the considerable clinical overlap between HD and dentatorubral-pallidoluysian atrophy (DRPLA) may warrant a recommendation of DRPLA gene testing in those patients referred with a clinical diagnosis of "HD" who subsequently test negative for the expansion. ${ }^{33}$

HD4.3.3 Comments on the significance of mutable normal alleles and $\mathrm{HD}$ alleles with reduced penetrance should not be over-interpreted in the absence of specific and well-documented clinical and/or family histories. Laboratories should be familiar with the published data on these CAG repeat length descriptors and be able to articulate an interpretation that balances these data with the specific patient/pedigree information provided to the diagnostic laboratory at the time of testing. ${ }^{6-9,34-35}$

\section{ACKNOWLEDGMENTS}

The authors wish to thank Dr. Michael S. Watson (Executive Director of the American College of Medical Genetics), and the members of the Laboratory Quality Assurance Committee (Dr. Carolyn Sue Richards, Chair) for their assistance and careful and thorough review of this manuscript.

\section{References}

1. Nance MA, Seltzer W, Ashizawa T, Bennett R, McIntosh N, Myers RH et al. ACMG/ ASHG Statement. Laboratory guidelines for Huntington disease genetic testing. Am J Hum Genet 1998;62:1243-1247.

2. Kremer B, Goldberg P, Andrew SE, Theilmann J, Telenius H, Zeisler J et al. A worldwide study of the Huntington's disease mutation. The sensitivity and specificity of measuring CAG repeats. N Engl J Med 1994;330:1401-1406.

3. McGlennen RC, Allinson PS, Matthias-Hagen VL, Parker TL, Lovell MA, Kelley TE. Evidence of an unstable paternal 27 CAG repeat allele in the huntingtin gene giving rise to clinically overt Huntington disease in a patient with the genotype (17/38). Am J Hum Genet 1995;57:A246.

4. Myers RH, MacDonald ME, Koroshetz WJ, Duyao MP, Ambrose CM, Taylor SAM et al. De novo expansion of a (CAG)n repeat in sporadic Huntington's disease. Nature Genet 1993;5:168-173.

5. Goldberg YP, Kremer B, Andrew SE, Theilman J, Graham RK, Squitieri F et al. Molecular analysis of new mutations for Huntington's disease: intermediate alleles and sex of origin effects. Nature Genet 1993;5:174-179.

6. Goldberg YP, McMurray CT, Zeisler J, Almqvist E, Sillence D, Richards F et al. Increased instability of intermediate alleles in families with sporadic Huntington disease compared to similar sized intermediate alleles in the general population. Hum Molec Genet 1995;4:1911-1918.

7. Chong SS, Almqvist E, Telenius H, LaTray L, Nichol K, Bourdelat-Parks B et al. Contribution of DNA sequence and CAG size to mutation frequencies of intermediate alleles for Huntington disease: evidence from single sperm analysis. Hum Molec Genet 1997;6:301-309.

8. Rubinsztein DC, Leggo J, Coles R, Almqvist E, Biancalana V, Cassiman J-J et al. Phenotypic characterization of individuals with 30-40 CAG repeats in the Huntington disease (HD) gene reveals HD cases with 36 repeats and apparently normal elderly individuals with 36-39 repeats. Am J Hum Genet 1996;59:16-22.

9. Brinkman RR, Mezei MM, Theilman J, Almqvist E, Hayden MR. The likelihood of being affected with Huntington disease by a particular age, for a specific CAG size. Am J Hum Genet 1997;60:1202-1210. 
10. Nance MA, Mathias-Hagen V, Breningstall G, Wick MJ, McGlennen RC. Analysis of a very large trinucleotide repeat in a patient with juvenile Huntington's disease. Neurology 1999;52:392-394.

11. Telenius H, Kremer B, Goldberg YP, Theilman J, Andrew SE, Zeisler J et al. Somatic and gonadal mosaicism of the Huntington disease gene CAG repeat in brain and sperm. Nature Genet 1994;6:409-413.

12. American College of Medical Genetics. Standards and guidelines for clinical genetics laboratories, 3rd edition. American College of Medical Genetics, 2002.

13. The Huntington's disease collaborative research group. A novel gene containing a trinucleotide repeat that is expanded and unstable on Huntington's disease chromosomes. Cell 1993;72:971-983.

14. Reiss O, Norremoelle A, Soerensen SA, Epplen JT. Improved PCR conditions for the stretch of (CAG)n repeats causing Huntington 's disease. Hum Mol Genet 1993;2: 637

15. Valdes JM, Tagle DA, Elmer IW, Collins FS. A simple non-radioactive method for the diagnosis of Huntington's disease. Hum Mol Genet 1993;2:633-634.

16. Warner JP, Barron L, Brock DJP. A new polymerase chain reaction (PCR) assay for the trinucleotide repeat that is unstable and expanded in Huntington's disease. $\mathrm{Mol}$ Cell Probes 1993;7:235-239.

17. Andrew SE, Goldberg YP, Theilman J, Zeisler J, Hayden MR. A CCG repeat polymorphism adjacent to the CAG repeat in the Huntington disease gene: Implications for diagnostic accuracy and predictive testing. Hum Mol Genet 1994;3:65-67.

18. Le H, Fung D, Trent RJ. Applications of capillary electrophoresis in DNA mutation analysis of genetic disorders. Mol Pathol 1997;50:261-265.

19. Williams LC, Hegde MR, Herrera G, Stapleton PM, Love DR. Comparative semiautomated analysis of (CAG) repeats in the Huntington disease gene: Use of internal standards. Mol Cell Probes 1999;13:283-289.

20. Bruland O, Almqvist EW, Goldberg YP, Bowman H, Hayden MR. Accurate determination of the number of CAG repeats in the Huntington disease gene using a sequence-specific internal DNA standard. Clin Genet 1999;55:198-202.

21. Gambardella A, Muglia M, Labate A, Magariello A, Gabriele AL, Mazzei R et al. Juvenile Huntington's disease presenting as progressive myoclonic epilepsy. Neurology 2001;57:708-711.

22. Cross G, Pitt T, Sharif A, Bates G, Lehrach H. False-negative result for Huntington's disease. The Lancet 1994;343:1232.

23. Gellera C, Meoni C, Castellotti B, Zappacosta B, Girotti F, Taroni F et al. Errors in Huntington disease diagnostic test caused by trinucleotide deletion in the IT15 gene. Am J Hum Genet 1996;59:475-477.
24. Margolis RL, Stine CO, Callahan C, Rosenblatt A, Abbott MH, Sherr M et al. Two novel single-base-pair substitutions adjacent to the CAG repeat in the Huntington disease gene (IT15): implications for diagnostic testing. Am J Hum Genet 1999;64: 323-326.

25. Williams LC, Hegde MR, Nagappan R, Faull RLM, Giles J, Winship I et al. Null alleles at the Huntington disease locus: implications for diagnostics and CAG repeat instability. Genet Test 2000;4:55-60.

26. Yu S, Fimmel A, Fung D, Trent RJ. Polymorphisms in the CAG repeat: A source of error in Huntington disease DNA testing. Clin Genet 2000;58:469-472.

27. Guida M, Fenwick RG, Papp AC, Snyder PJ, Sedra M, Prior TW. Southern transfer protocol for confirmation of Huntington disease. Clin Chem 1996;42:1711-1712.

28. Andrew SE, Goldberg YP, Kremer B, Squitieri F, Theilman J, Zeisler J et al. Hun tington disease without CAG expansion: Phenocopies or errors in assignment? Am J Hum Genet 1994;54:852-863.

29. Rosenblatt A, Ranen NG, Rubinsztein DC, Stine OC, Margolis RL, Wagster MV et al. Patients with features similar to Huntington's disease, without CAG expansion in huntingtin. Neurology 1998;51:215-220.

30. Moore RC, Xiang F, Monaghan J, Han D, Zhang Z, Edstrom L et al. Huntington disease phenocopy is a familial prion disease. Am J Hum Genet 2001;69:1385-1388.

31. Margolis RL, O'Hearn E, Rosenblatt A, Willour V, Holmes SE, Franz ML et al. A disorder similar to Huntington's disease is associated with a novel CAG repeat expansion. Ann Neurol 2001;50:373-380.

32. Holmes SE, O'Hearn E, Rosenblatt A, Callahan C, Hwanf HS, Ingersoll-Ashworth $\mathrm{RG}$ et al. A repeat expansion in the gene encoding junctophilin-3 is associated with Huntington disease-like 2. Nature Genet 2001;29:377-378.

33. Potter NT, Meyer MA, Zimmerman AW, Eisenstadt ML, Anderson IJ. Molecular and clinical findings in a family with dentatorubral-pallidoluysian atrophy. Ann Neurol 1995;37:273-277.

34. Maat-Kievit A, Helderman-van-den Enden P, Losekoot M, de Knijff P, Belfroid R, Vegter-van der Vlis $\mathrm{M}$ et al. Using a roster and haplotyping is useful in risk assessment for persons with intermediate and reduced penetrance alleles in Huntington disease. Am J Med Genet 2001;105:737-744.

35. Maat-Kievit A, Losekoot M, van den Boer-van den Berg H, van Ommen G-J, Niermeijier M, Breuning $M$ et al. New problems in testing for Huntington's disease: the issue of intermediate alleles and reduced penetrance. J Med Genet $2001 ; 38: 12 \mathrm{e}-12$.

Disclaimer: These standards and guidelines are designed primarily as an educational resource for clinical laboratory geneticists to help them provide quality clinical laboratory genetic services. Adherence to these standards and guidelines does not necessarily ensure a successful medical outcome. These standards and guidelines should not be considered inclusive of all proper procedures and tests or exclusive of other procedures and tests that are reasonably directed to obtaining the same results. In determining the propriety of any specific procedure or test, the clinical molecular geneticist should apply his or her own professional judgment to the specific clinical circumstances presented by the individual patient or specimen. It may be prudent, however, to document in the laboratory record the rationale for any significant deviation from these standards and guidelines. 